\section{Gibberellic Acid-induced Seedlessness in Field-grown Vines of 'Swenson Red' Grape}

\author{
Cynthia Fellman', Emily Hoover ${ }^{2}$, Peter D. Ascher ${ }^{3}$, and \\ James Luby ${ }^{2}$ \\ Department of Horticultural Science, University of Minnesota, 1970 \\ Folwell Avenue, St. Paul, MN 55108 \\ Additional index words. grape, growth regulator, parthenocarpy
}

\begin{abstract}
We evaluated the extent to which 'Swenson Red' seeded grape (Vitis $\times$ spp.) responded to single and repeated $\mathrm{GA}_{3}$ applications to induce seedless fruit development. Field studies were conducted to test the time of pre-anthesis $\mathrm{GA}_{3}$ application $(18$, or 24 May or 3 June), the usefulness of postanthesis application, the optimum $\mathbf{G A}_{3}$ concentration $(0,0.075,0.15$, or $0.3 \mathrm{~mm})$, and the method of application. The treatment dates that gave a high percentage of seedless berries with an acceptable berry count per cluster were 24 May with postanthesis application and 3 June pre-anthesis only. The optimum $\mathrm{GA}_{3}$ concentration was $0.15 \mathrm{~mm}$ applied both before and after anthesis. The most seedless berries developed when pre- and postanthesis applications were used, indicating many seedless fruit developed from flowers that would have abscised. There was no difference in percent heedlessness, number of berries per cluster, or number of seeds per berry between clusters dipped or sprayed with 0.3 mM GA $_{3}$. Chemical uame used: gibberellic acid $\left(\mathrm{GA}_{3}\right)$.
\end{abstract}

$\mathrm{GA}_{3}$ is known to stimulate parthenocarpic fruit development in grapes and other fruits (Pharis and King, 1985). Clore (1965) and Ito et al. (1969) established that dipping flower bud clusters of $V \times$ labruscana 'Delaware' in $0.26 \mathrm{~mm}(100 \mathrm{ppm}) \mathrm{GA}_{3} \approx 10$ days before and again 10 days after anthesis resulted in nearly $100 \%$ seedless fruit. Pratt and Shaulis (1961) also obtained a high percentage of seedless fruit with 'Fredonia' grapes, especially under conditions of reduced or inhibited pollination. In many other cases, however, $\mathrm{GA}_{3}$ failed to induce seedlessness (Motomura and Hori, 1978); thus, cultivars need to be evaluated individually for this characteristic.

The objective of the following studies was to evaluate the response of Vitis $\times \mathrm{spp}$. 'Swenson Red' to single and repeated applications of $\mathrm{GA}_{3}$ under field conditions to stimulate seedless fruit development. 'Swenson Red' is a high-quality, seeded table grape able to reliably survive temperatures common to Minnesota winters.

Vines of 'Swenson Red' used in the 1985 and 1986 field studies were grown at the Univ. of Minnesota Horticultural Research Center near Excelsior. Vines were planted in 1979 at a $2-\mathrm{m}$ spacing, trained to double upper cordons, and cane-pruned. Vines were

Received for publication 28 Aug. 1989. Paper no. 18,385 of the Scientific Journal Series, Univ. of Minnesota Agricultural Experiment Station. The cost of publishing this paper was defrayed in part by the payment of page charges. Under postal regadvertisement solely to indicate this fact.

${ }^{1}$ Former Graduate Student. Current address: Horticulture Education Dept., Frank's Nursery \& Crafts, 6399 E. Nevada, Detroit, MI 48234. ${ }^{2}$ Associate Professor.

${ }^{3}$ Professor. ulations, this paper therefore must be hereby marked pruned in early spring, and summer pruning was performed as necessary to control vigor.

In 1985, 10 canes, each bearing two inflorescences, were randomly selected on each of three dates (18 and 24 May and 3 June). Ten additional canes with two inflorescences each were selected to receive a water control on 18 May. Inflorescences were dipped in $0.26 \mathrm{~mm}$ potassium salt of GA, or water (both solutions contained a small amount of Tween 20 as a surfactant) and agitated briefly to dislodge air bubbles. Both inflorescences on each shoot received the same pre-anthesis treatment. On 17 June (corresponding to fruit set for clusters with $\mathrm{GA}_{3}$ on 18 May), 0.26 $\mathrm{mm} \mathrm{GA}_{3}$ was applied to the distal cluster on each cane, including shoots that received only water as a preanthesis treatment. There were no nontreated distal clusters, and interaction between clusters on the same cane was assumed to be nonexistent. The experiment was a completely randomized design with four and two treatment levels of two factors: preanthesis and postanthesis $\mathrm{GA}_{3}$ application, respectively. Data were subjected to arcsin transformation for analysis of variance and back-transformed for presentation.

Three factors were studied in 1986: GA concentration necessary to induce seedlessness $(0,0.075,0.15$, and $0.3 \mathrm{~mm})$, application method (spraying vs. dipping clusters), and time of application (pre-anthesis, postanthesis, and pre- + postanthesis). Three canes on each of 10 vines were selected to receive the same $\mathrm{GA}_{3}$ concentration but at different application times: pre-anthesis (27 May), postanthesis (18 June), or pre- + postanthesis (same dates). Another 10 vines were selected to compare application method at the highest $\mathrm{GA}_{3}$ rate, again with the same application times. All canes were thinned to one inflorescence each at the time of pre-anthesis application.

This experiment had been designed as a split plot with the plant as the main plot. However, because many shoots were winddamaged and bird injury to fruit was substantial, data were analyzed according to a completely randomized design. Again, data were arcsin-transformed for analysis and backtransformed for presentation.

In both years, clusters from all treatments were harvested at the same time, when the

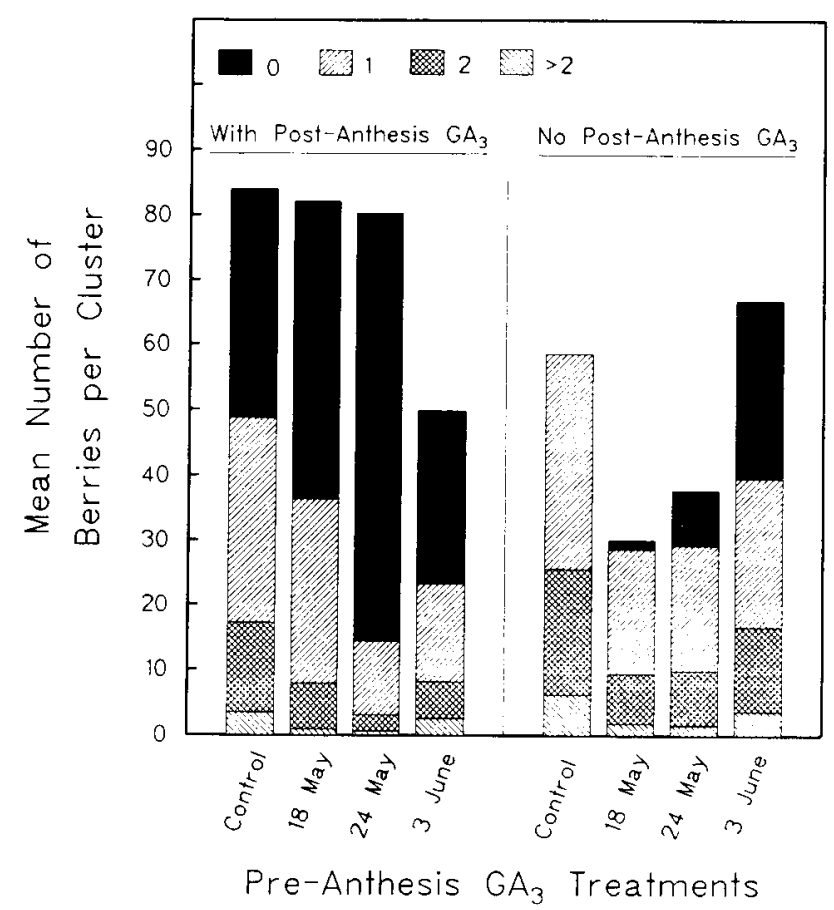

Fig. 1. Effect of pre- and postanthesis application of $0.26 \mathrm{~mm} \mathrm{GA}_{3}$ on number of berries per cluster and on the number of seeds per berry for 'Swenson Red', 1985. 


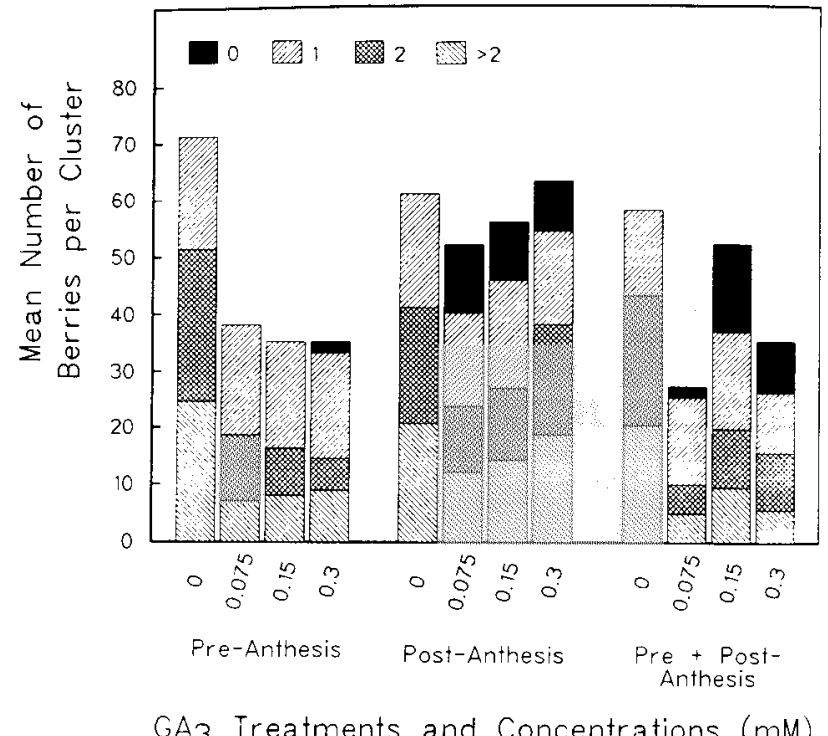

Fig. 2. Effect of pre- and postanthesis $\mathrm{GA}_{3}$ application on number of berries per cluster and number of seeds per berry for 'Swenson Red', 1986.

Table 1. Effects of pre-anthesis and postanthesis $\mathrm{GA}_{3}(0.26 \mathrm{~mm}$ application on fruit set and seedlessness of 'Swenson Red' in 1985.

\begin{tabular}{lccc}
\hline \hline $\begin{array}{l}\text { Pre/postanthesis } \\
\text { treatment }\end{array}$ & $\begin{array}{c}\text { Seedless } \\
\text { berries/cluster } \\
(\%)\end{array}$ & $\begin{array}{c}\text { Berries/cluster } \\
\text { (no.) }\end{array}$ & $\begin{array}{c}\text { Seeds/berry } \\
\text { (no.) }\end{array}$ \\
\hline Control/0 & $0 \mathrm{~b}$ & $65.0 \mathrm{a}$ & $1.74 \mathrm{a}$ \\
$18 \mathrm{May} / 0$ & $3.5 \mathrm{~b}$ & $30.9 \mathrm{~b}$ & $1.48 \mathrm{a}$ \\
$24 \mathrm{May} / 0$ & $23.1 \mathrm{ab}$ & $39.1 \mathrm{~b}$ & $1.14 \mathrm{a}$ \\
$3 \mathrm{June} / 0$ & $37.9 \mathrm{a}$ & $70.4 \mathrm{a}$ & $1.06 \mathrm{a}$ \\
Control/GA & $46.5 \mathrm{~b}$ & $87.4 \mathrm{a}$ & $0.95 \mathrm{a}$ \\
$18 \mathrm{May} / \mathrm{GA}_{3}$ & $51.4 \mathrm{~b}$ & $91.4 \mathrm{a}$ & $0.63 \mathrm{a}$ \\
$24 \mathrm{May} / \mathrm{GA}_{3}$ & $80.2 \mathrm{a}$ & $80.5 \mathrm{a}$ & $0.24 \mathrm{~b}$ \\
$3 \mathrm{June} / \mathrm{GA}_{3}$ & $48.3 \mathrm{~b}$ & $49.9 \mathrm{~b}$ & $0.81 \mathrm{a}$ \\
Effect of pre-anthesis treatment & $* *$ & $\mathrm{NS}$ & $* *$ \\
Effect of postanthesis treatment & $* *$ & $* *$ & $*$ \\
Interaction & $* *$ & $* *$ & $*$
\end{tabular}

${ }^{2}$ Means separation within columns and among postanthesis treatments by Tukey's HSD $_{0.05}$ values. Data represent means of eight randomly selected clusters.

NS.*.**Nonsignificant or significant at $P=0.05$ or 0.01 , respectively.

Table 2. Effects of $\mathrm{GA}_{3}$ concentration and use of postanthesis $\mathrm{GA}_{3}$ application on fruit set and seedlessness of 'Swenson Red' in 1986.

\begin{tabular}{llccc}
\hline \hline & $\begin{array}{c}\mathrm{GA} \\
\text { concn } \\
\text { Time of application }\end{array}$ & $\begin{array}{c}\text { Seedless } \\
\text { berries/cluster } \\
(\mathrm{mM})\end{array}$ & $\begin{array}{c}\text { Berries/cluster } \\
\text { (no.) }\end{array}$ & $\begin{array}{c}\text { Seeds/berry } \\
\text { (no.) }\end{array}$ \\
\hline Pre-anthesis & 0 & 0 & 71.3 & 2.25 \\
& 0.075 & 0 & 39.6 & 1.74 \\
& 0.15 & 0 & 35.3 & 1.65 \\
Postanthesis & 0.3 & 4.1 & 30.9 & 1.44 \\
& 0 & 0 & 60.6 & 2.25 \\
Both & 0.075 & 19.7 & 54.8 & 1.60 \\
& 0.15 & 17.3 & 56.6 & 1.62 \\
& 0.3 & 10.7 & 64.8 & 1.80 \\
Effect of application time & 0 & 0 & 57.0 & 2.14 \\
Effect of GA concentration & 0.075 & 7.6 & 27.5 & 1.64 \\
Interaction & 0.15 & 30.4 & 52.6 & 1.32 \\
N & 0.3 & 1.0 & 33.0 & 1.79 \\
\hline
\end{tabular}

NS,*,**Nonsignificant or significant at $P=0.05$ or 0.01 , respectively.

$\mathrm{GA}_{3}$-treated clusters had completed veraison and were ripening. Berries were sliced equatorially, the number of seeds per berry counted, and the berries were categorized according to seed count.

In 1986, no statistical difference was de- tected between the two application methods, and the data, therefore, were pooled.

$\mathrm{GA}_{3}$ application either before or after anthesis induced seedless fruit development. In fact, the majority of berries in the 18 and 24 May treatments that received both pre-an- thesis and postanthesis applications were seedless (Table 1). In 1986, postanthesis treatment also increased percent heedlessness at all $\mathrm{GA}_{3}$ concentrations (Table 2); seedless berries were induced only when a postanthesis application was used, except at 0.3 $\mathrm{mm} \mathrm{GA}_{3}$, where a few seedless berries were induced with a preanthesis application alone.

In both 1985 and 1986, clusters receiving postanthesis application usually had more berries than clusters receiving only a preanthesis application (Tables 1 and 2). The only exceptions were the 3 June application in 1985 and the 0.075 and $0.3 \mathrm{~mm}$ pre + postanthesis applications in 1986. Pre-anthesis $\mathrm{GA}_{3}$ treatment without a postanthesis application reduced berry count per cluster, except for the 3 June treatment in 1985.

Pre-anthesis or postanthesis $\mathrm{GA}_{3}$ treatments reduced the mean number of seeds per berry, although the reduction was not as great in 1986 as in 1985 (Tables 1 and 2).

The mode of action of $\mathrm{GA}_{3}$-induced parthenocarpy is unclear. The accepted mechanism (Motomura and Ito, 1972) states that pre-anthesis application of $\mathrm{GA}_{3}$ "kills" ovules and that postanthesis application stimulates subsequently seedless fruit to develop to maturity. Other evidence (Fellman, 1989) suggests pre-anthesis $\mathrm{GA}_{3}$ creates "developmental incongruity" between the pistil and the embryo sac; pistil development is accelerated, but development of the embryo sac does not change, the result being failure of double fertilization and lack of seed development. In addition, Fellman (1989) found the degree of developmental incongruity lessened over the flowering period, indicating earlier-opening flowers were more likely to be seedless than later-opening ones.

The difference in berry number per cluster between clusters receiving $\mathrm{GA}_{3}$ before vs. after anthesis appeared to consist largely of seedless berries (Figs. 1 and 2). Perhaps, $\mathrm{GA}_{3}$ stimulated nonfertilized or otherwise nonviable fruit to be retained. The exceptions are significant in that the pre-anthesis 3 June treatment without postanthesis application was probably late enough to stimulate already nonviable flowers to continue development similar in effect to a postanthesis treatment. Likewise, the addition of a postanthesis application for this treatment was perhaps excessive, resulting in thinning of the berries. In 1986, postanthesis treatments resulting in decreases in berry count per cluster were probably due to inadequate or excessive $\mathrm{GA}_{3}$ concentrations.

The low percentage of seedless berries from the 1986 study, compared to 1985 , could, perhaps, be explained by environmental conditions, although high temperatures $(\geq 30 \mathrm{C}$; Motomura and Hori, 1977) did not appear to be the cause during our experiments.

The optimal time for $\mathrm{GA}_{3}$ application is not well defined. External markers used to determine stage of inflorescence development are subjective and prone to error. The literature describes the optimal time as when individual florets on the inflorescence are slightly separated (Ito et al., 1969). A slight misjudgements could easily result in a sub- 
stantial increase in seeded berries or in no berries at all (Motomura and Ito, 1972). A more accurate and, hence, more meaningful description of inflorescence development, perhaps based on growing degree days, could help remove subjectivity. Until then, the wide year-to-year variability and increased labor costs associated with repeated applications make the commercial use of $\mathrm{GA}_{3}$-induced parthenocarpy limited. Further research under field and controlled environments is necessary to better understand conditions that result in parthenocarpic fruit development. With a thorough comprehension of the mechanism of $\mathrm{GA}_{3}$-induced seedlessness, fruit producers may be able to better manipulate this growth regulator.

\section{Literature Cited}

Clore, W.J. 1965. Responses of Delaware grapes to gibberellin. Proc. Amer. Soc. Hort. Sci. $87: 259-263$.

Fellman, C.D. 1989. Gibberellic acid-induced developmental incongruity in floral buds of Vitis sp. 'Swenson Red'. PhD Diss., Univ. of Minnesota, St. Paul.

Ito, H., Y. Motomura, Y. Konno, and T. Hatayama. 1969. Exogenous gibberellin application as responsible for the seedless berry development of grapes. I. Physiological studies on the development of seedless 'Delaware' grapes. Tohoku J. Agr. Res. 20:1-18.

Motomura, Y. and Y. Hori. 1977. Exogenous gibberellin as responsible for the seedless berry development of grapes. IV. Effects of temperature on the activity of applied gibberellin on the heedlessness and seedless berry development in 'Delaware' and 'Campbell Early' grapes. Tohoku J. Agr. Res. 28:8-17.
Motomura, Y. and Y. Hori. 1978. Exogenous gibberellin as responsible for the seedless berry development of grapes. V. Explanation of GA effects on the induction of heedlessness and seedless berry development varying with cultivars. Tohoku J. Agr. Res.29:111-119.

Motomura, Y.and H. Ito. 1972. Exogenous gibberellin as responsible for the seedless berry development of grapes. II. Role and effects of the prebloom gibberellin application as concerned with the flowering, seedlessness and seedless berry development of 'Delaware' and 'Campbell Early' grapes. Tohoku J. Agr. Res. 23:15-32

Pharis, R.P. and R.W. King. 1985. Gibberellins and reproductive development in seed plants. Annu. Rev. Plant Phys. 36:517-568.

Pratt, C. and N.J. Shaulis. 1961. Gibberellin-induced parthenocarpy on grapes. Proc. Amer. Soc. Hort. Sci. 77:322-330. 